\title{
EFFECTIVENESS OF BRAIN-BASED LEARNING STRATEGIES AND LEARN GRAMMER IN MIDDLE LEVEL SCHOOL (MIND MAPPING STRATEGY MODEL)
} http://dx.doi.org/10.47832/2757-5403.4-3.13

\section{Naziha ZAKOUR ${ }^{1}$}

\begin{abstract}
:
Since the beginning of the twentieth century, especially at the beginning of the last decade of it the efforts of specialists and researchers in the field of education in general and in some other scientific branches relevant to language teaching in particular began as psychology, knowledge psychology and linguistics in both general and applied branches all these sciences strive to raise the level of education as well as learning so that they work to develop theories, methods and learning strategies in order to achieve the best results in education. The emergence of brain-based learning has been instrumental in illuminating how the brain works in its right and left hemispheres, which allows understanding of the work of the educated brain and the exploitation of its abilities and guidance to serve its educational interests, this has prompted researchers and theorists to focus on employing learning strategies that are compatible with the work of the human brain and to urge the need for them to be included in educational curricula as a refuge for both the teacher and the learner, In recent years, such strategies have become apparent in the Algerian school's educational milieu; Reliance was placed on these active strategies to increase learning and hold the learner's hand to discover and make the best use of his or her mental abilities.

In this paper, she follows a mind mapping strategy to answer a problem: How effective is a mind mapping strategy in bringing understanding and achievement closer to the learner in the subject of grammar for the intermediate third year(model) to underscore the importance of psychology strategy especially as it is one of the most important strategies which correspond to habits of mind of a learner who can use the most appropriate type of habit of mind to solve the learning problem in front of him the objective of this research paper is to encourage both the teacher and the learner to benefit from the mind mapping strategy and to realize the importance of the research on the
\end{abstract}

\footnotetext{
${ }^{1}$ Researcher, M'sila university, Algeria, naziha.zakour@univ-msila.dz, https://orcid.org/0000-0001-8412-2993
} 
functioning of the human brain and how it organizes the information for optimal use in the educational process.

Key words: Learning, Education, Brain Based Learning, Habits of Mind, Learning Strategies, Mind Mapping Stategy.

\title{
فاعلية استراتيجيات التعلم المستثد إلى الاماغ وتعلم النحو في مرحلة التعليم المتوسط

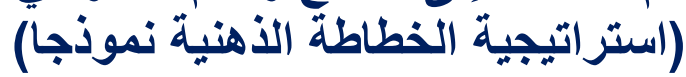

\author{
نزيهة زكور2
}

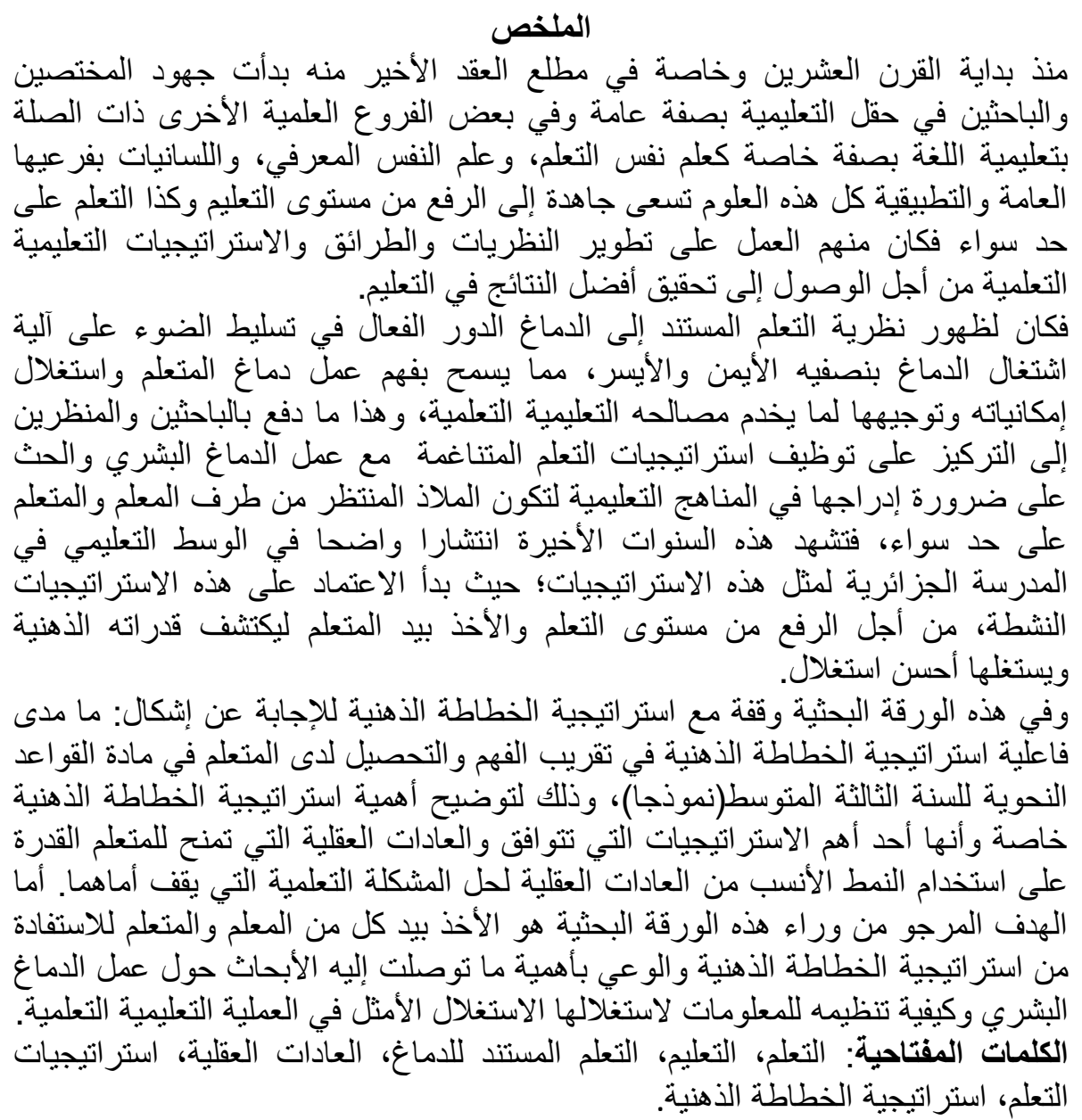

المقدَّمة:

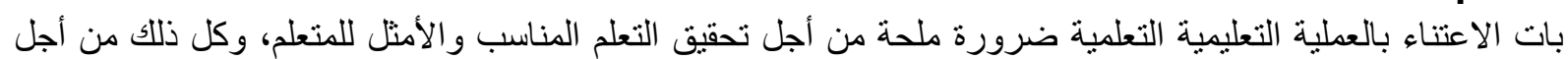

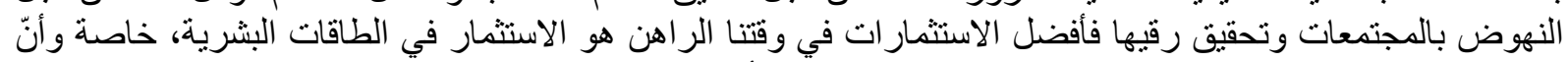

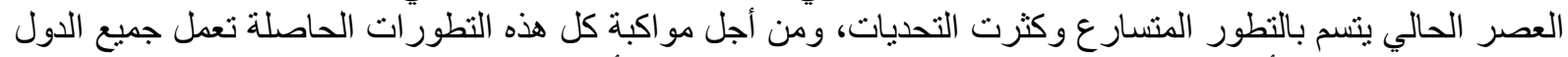

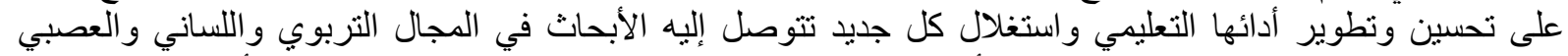

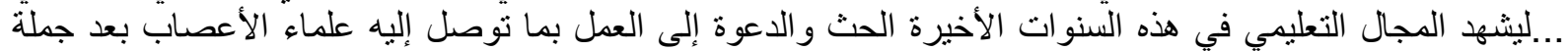

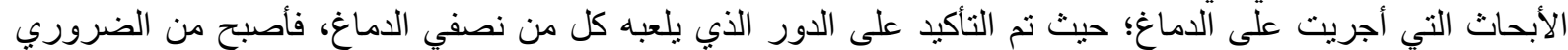

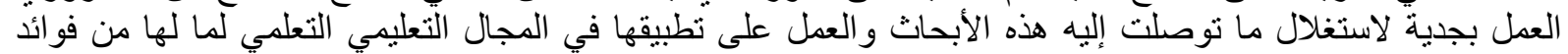
على المتعلم و المعلم على حد سو اءعل ماء. 
يعد التعلم المستند إلى الدماغ أحد الأساليب الحديثة و المهمة في تنمية التحصيل الدراسي لاى المتعلمين وكذا دوره الفعال

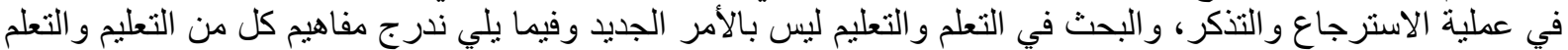

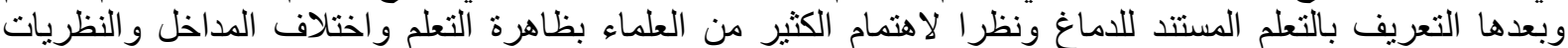

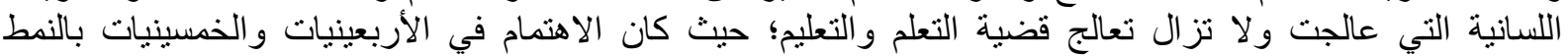

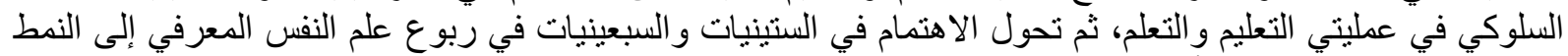

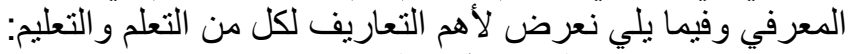

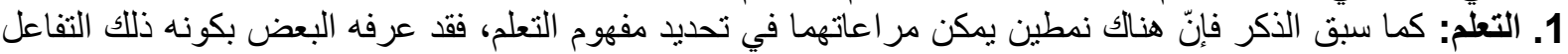

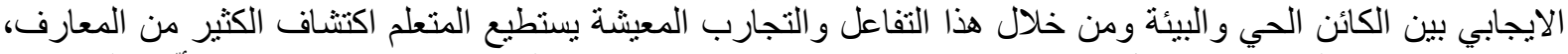

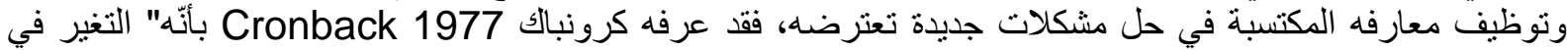

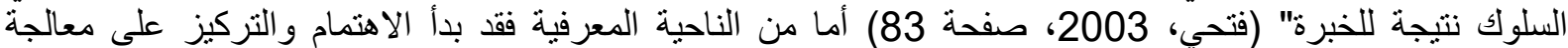

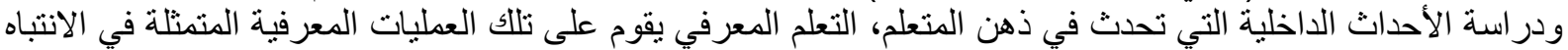

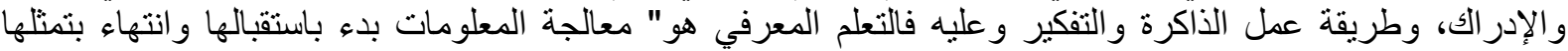

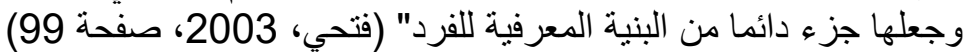

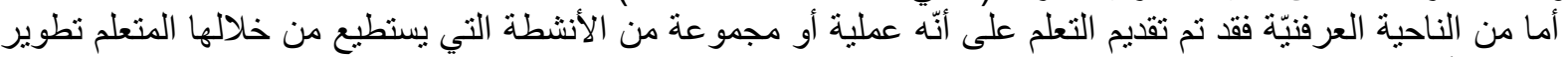

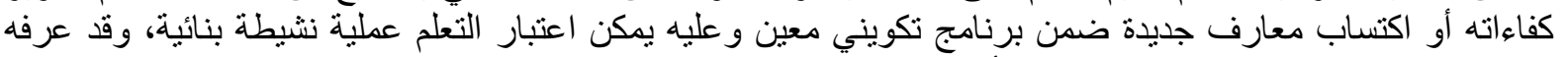

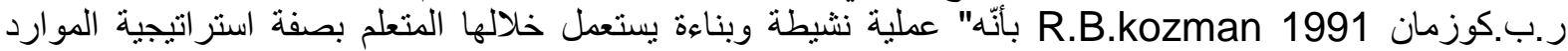

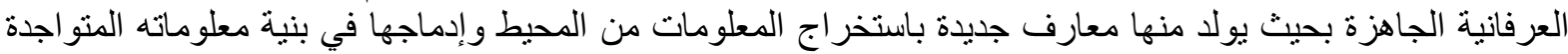

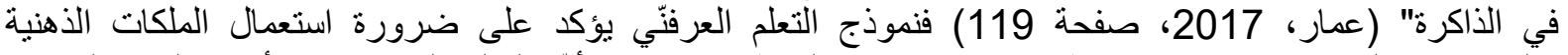

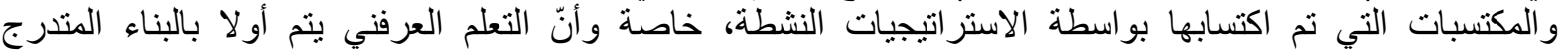

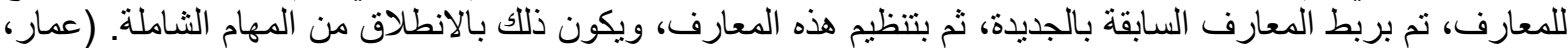

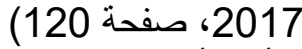

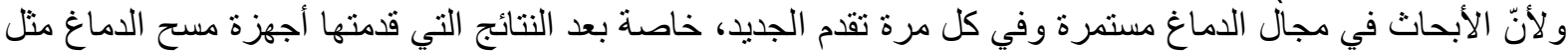

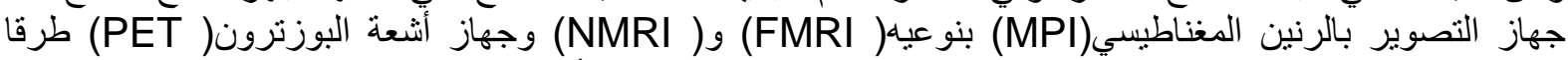

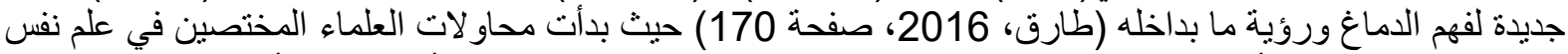

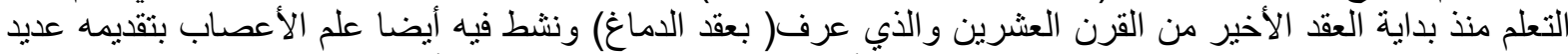

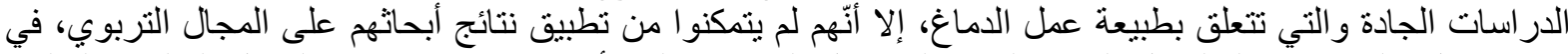

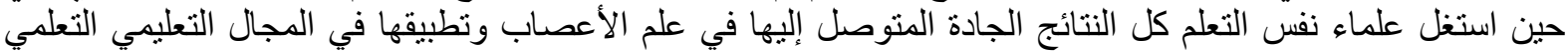

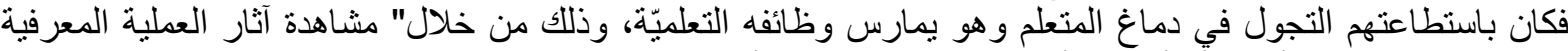

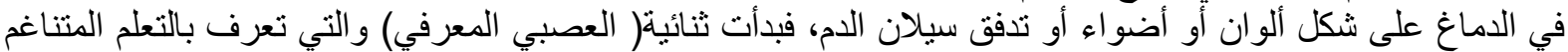

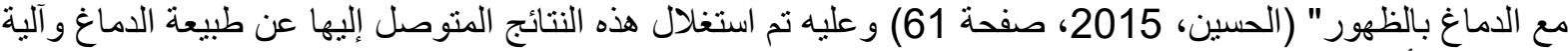
اشتغاله من أجل تحسين وتفعيل عمليتي التعليم و التعلم.

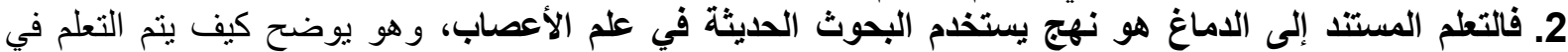

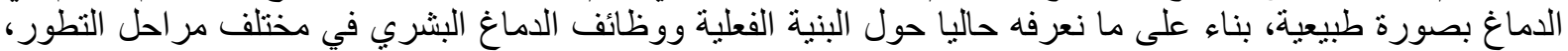

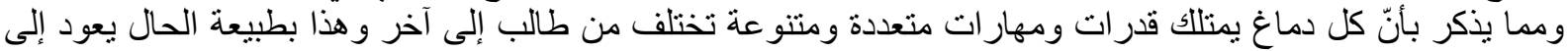

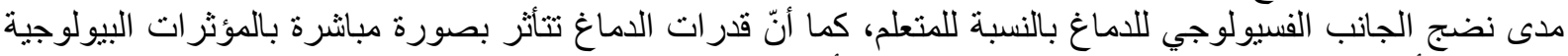

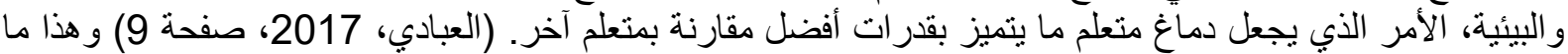

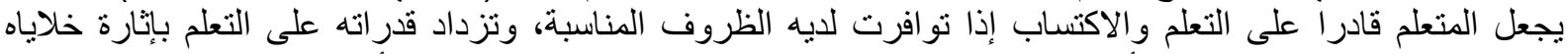

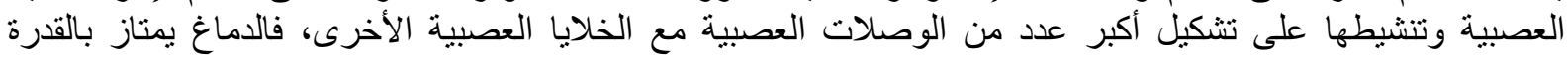
التكيفية مع المو اقف المختلفة. 


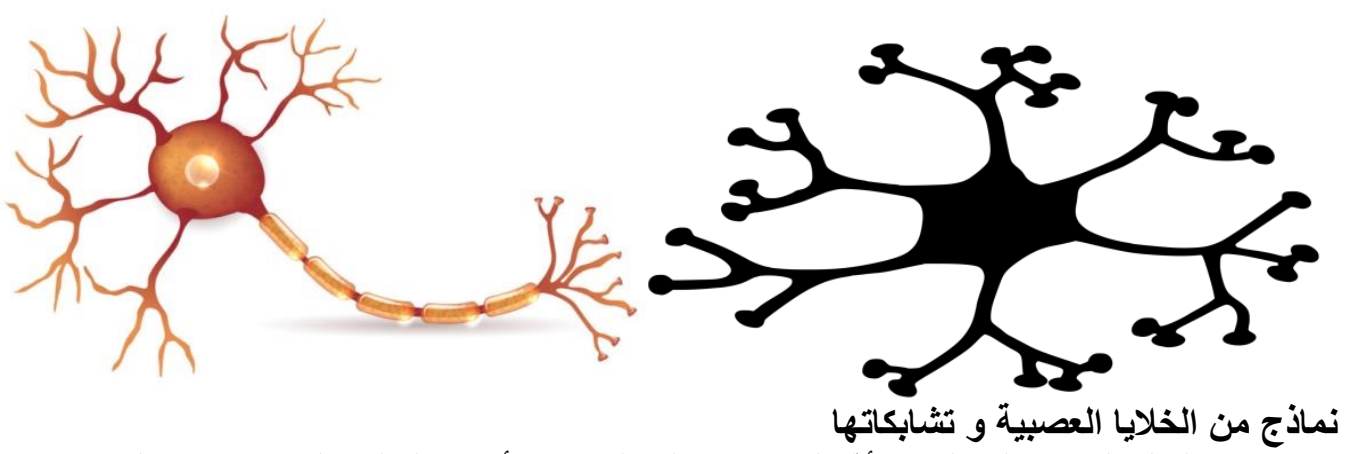

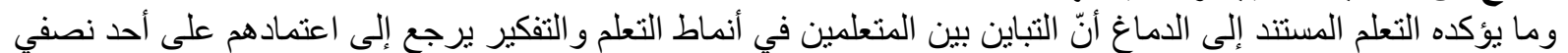

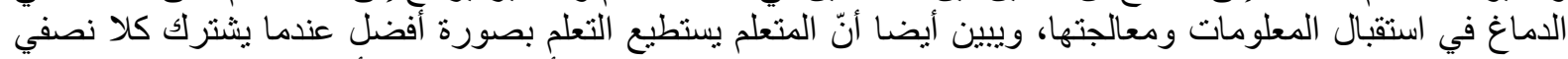

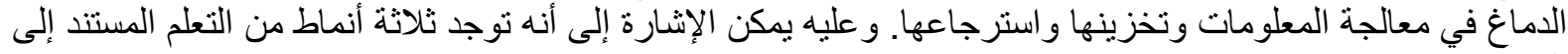

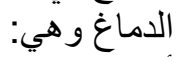
أولا: نمط ألتعلم المرتبط بالنصف الأيسر من الدماغ: يمتاز فيه المتعلمون بالميل إلى المعالجة التحليلية المنطقية اللفظية و الرقمية للمعلومات، وتفضيل الأعمال المخطط لها جيدا.

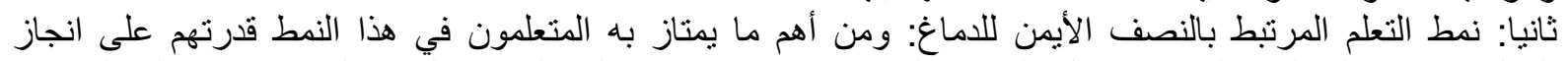

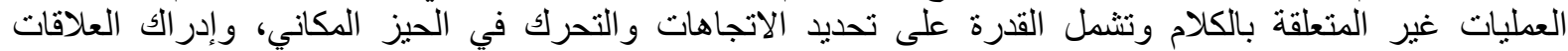

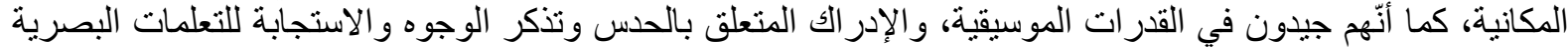

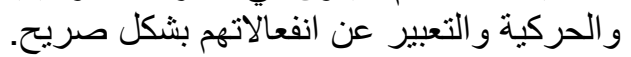

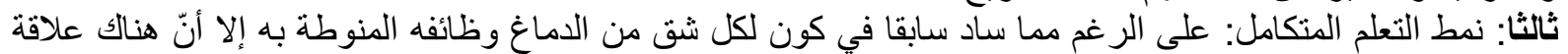

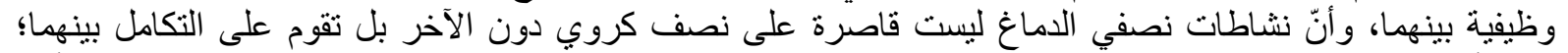

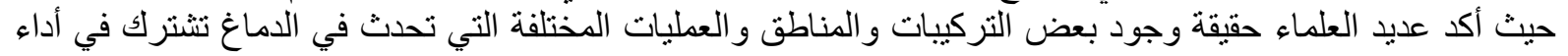

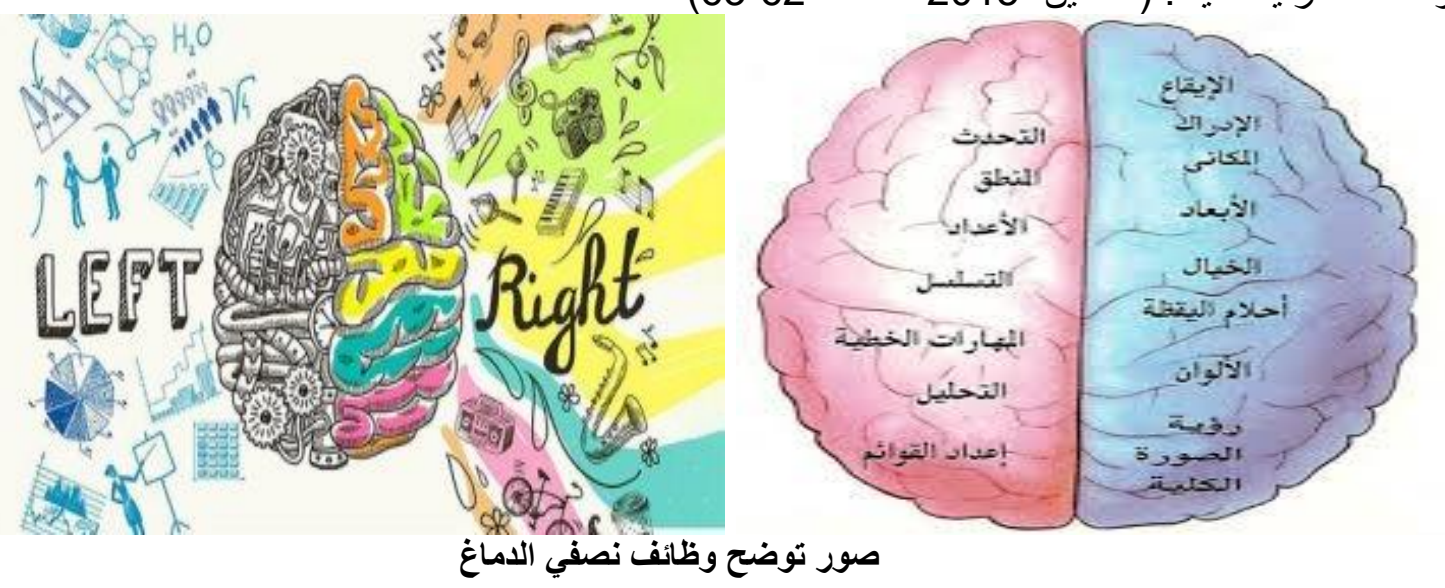

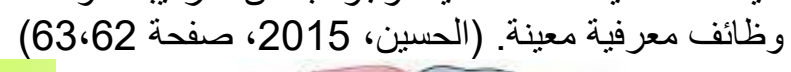

ونتيجة تسارع الأبحاث المتعلقة بالدماغ البشري ضمن علم الأعصاب، فكانت نتائجه المادية والفعالة التي قدمها من أجل

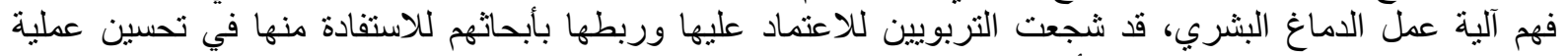

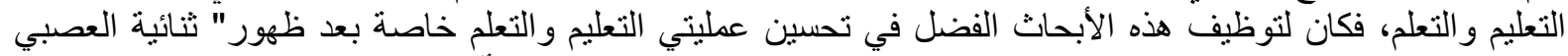

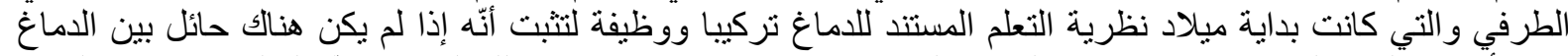

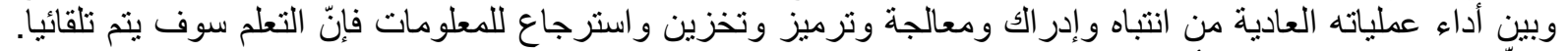

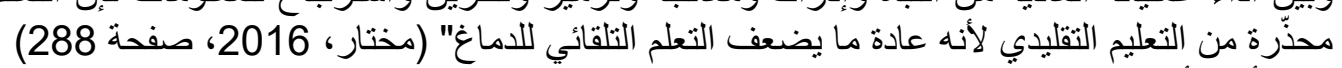

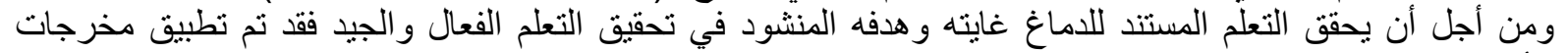

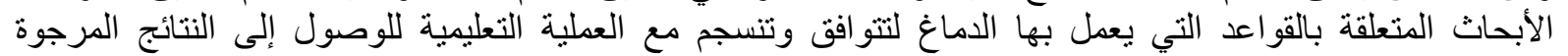

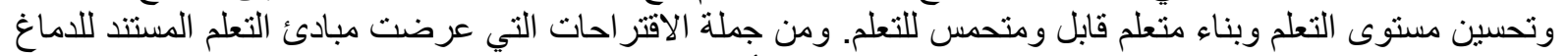

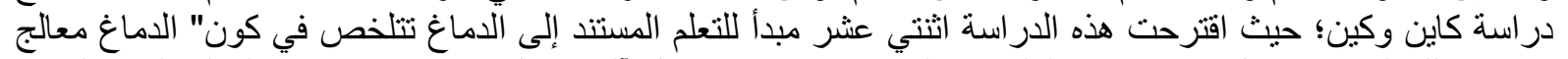

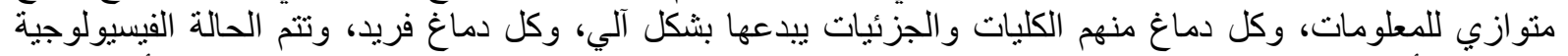

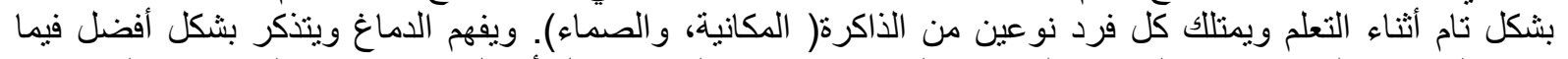

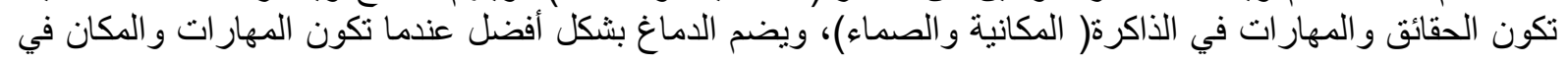




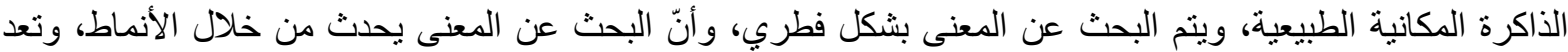

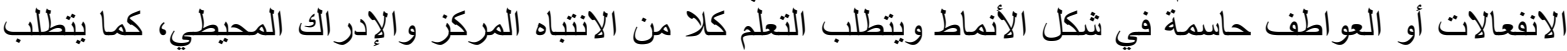

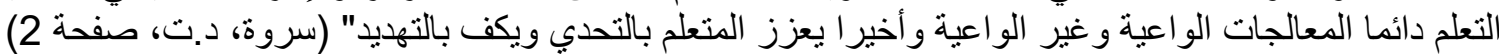

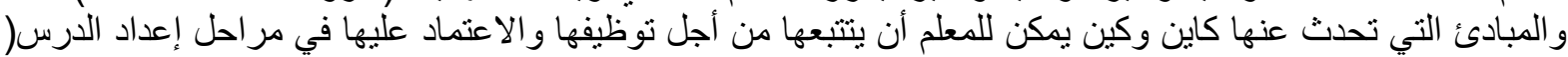

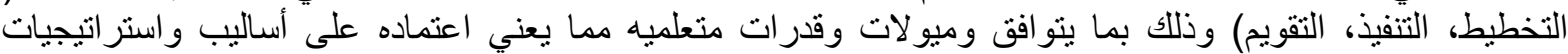

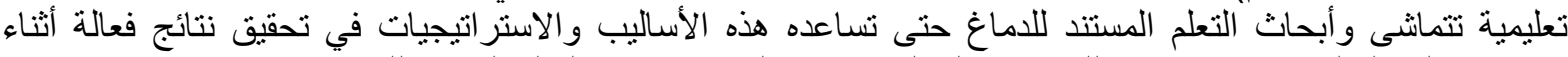

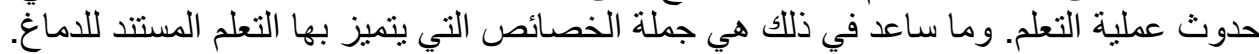

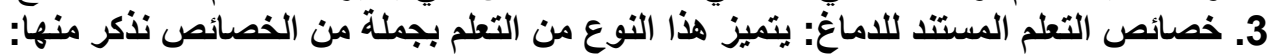

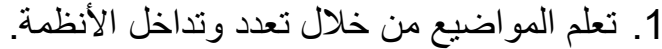

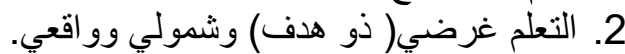
3. 3. نوظيف أنواع الذكاء المتعددة.

4. استثارة عالية وبشكل ملائم للانفعالات و وغياب التهاء التهديد.

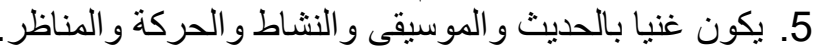

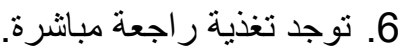

7. 8. 8 الدافعية داخلية والتقييم مستمر .

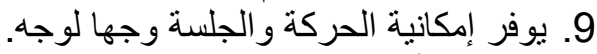

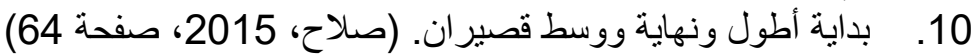

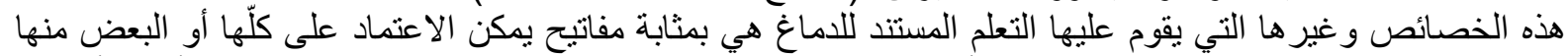

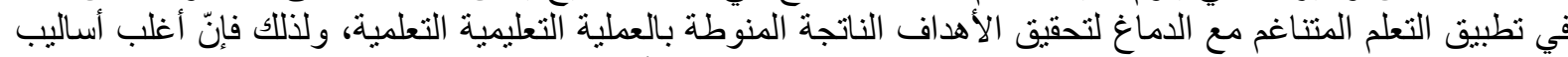

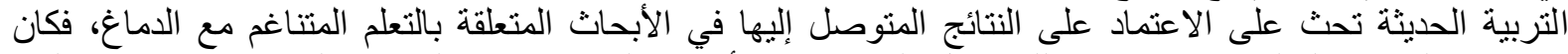

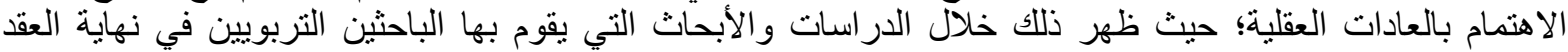

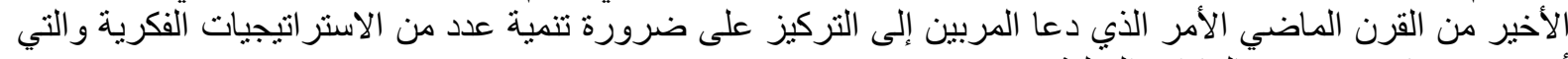

أصبحت فيما بعد تعرف بالعادات العات العقلية.

4. عادات العقل Hobit Mind: لا تعتبر العادات العقلية امتلاكا للمعلومات بل هي معرفة كيفية العمل عليها

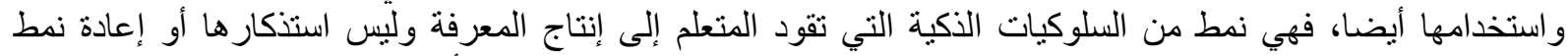

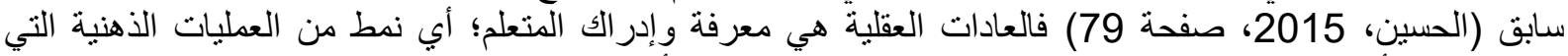

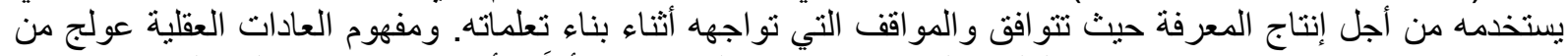
عدة زو ايا بحسب توجهات والهن التمامات العلماء الذين درسوا هذا الموضوع و وأولَوهُ أهمية كبيرة في علوم التربية وخاصة

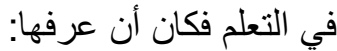
الإتجاه الأول: يرى أنّ العادات العقلية نمط من السلوكيات الذكية تقود المتعلم إلى أفعال، وهي تتكون نتيجة لاستجابة

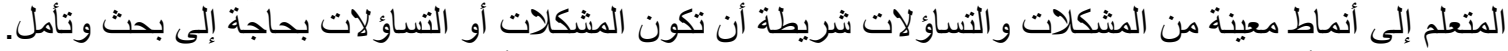

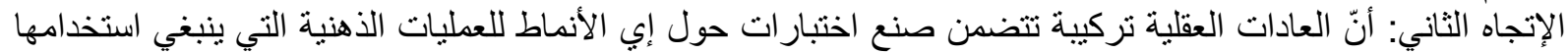

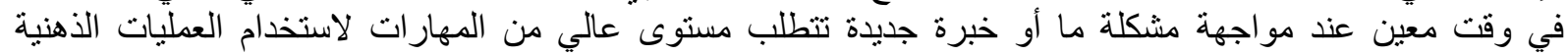
بصورة فاعلة وتنفيذها و المحافظة عليها.

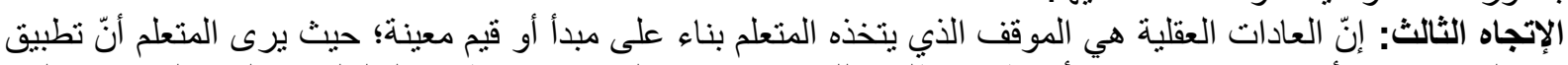

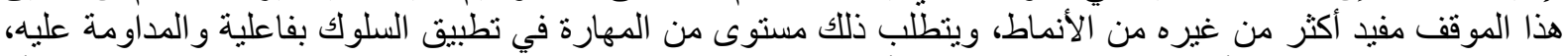

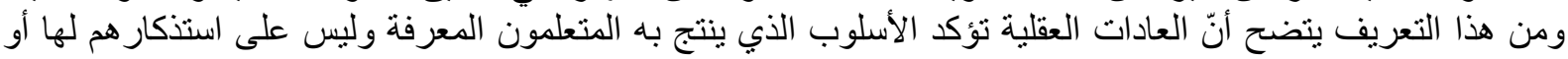

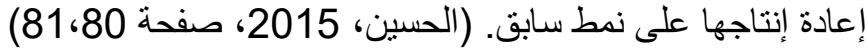

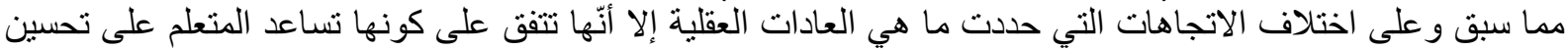

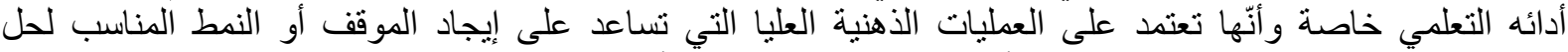

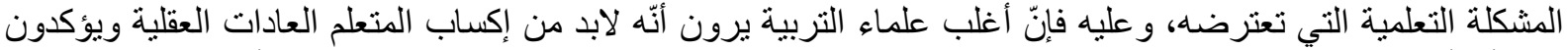

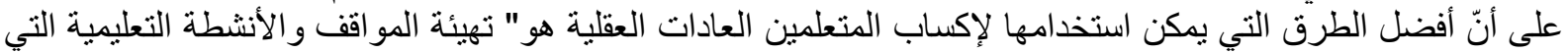

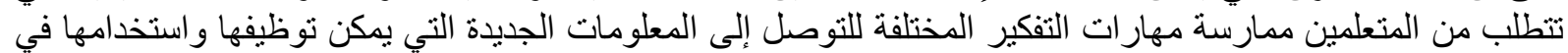

مو اقف ومشكلات حياتية" (الحسين، 2015، صفينة 


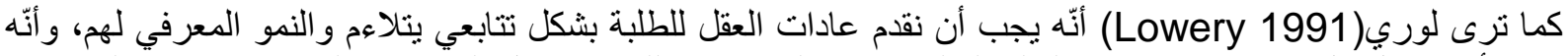

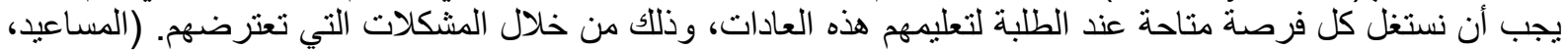

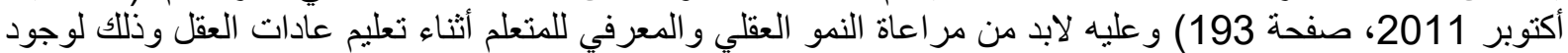

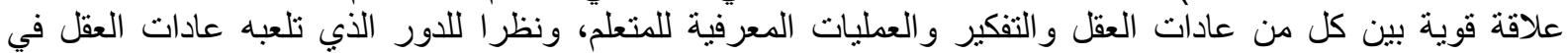

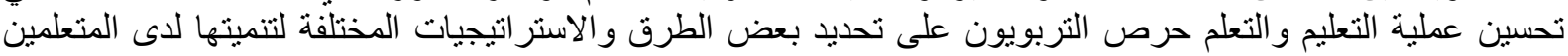

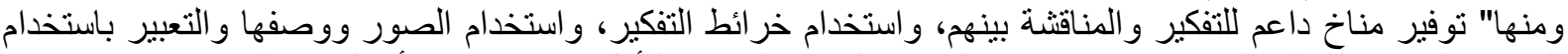

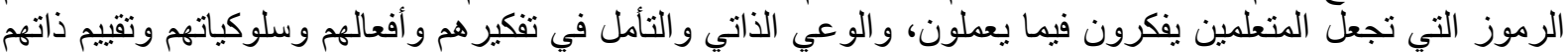

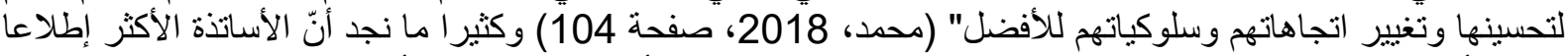

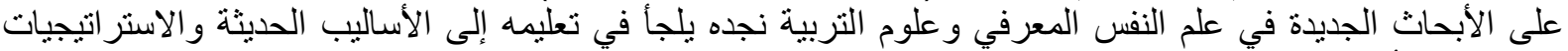

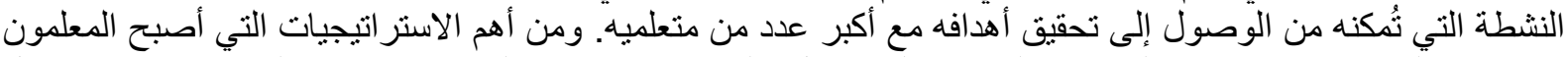

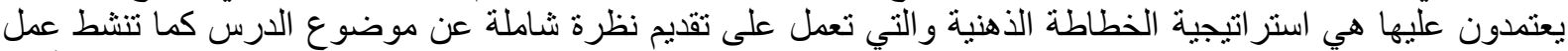
الذاكرة من تنظيم ترتيب للمعلومات بحيث يسهل استرجاع المعلومات، كما تشجع المتعلمين على ابتكار أفكار إبداعية تُعِل عمل المخ. 5. الخطاطة الذهنية: تم ابتكار الخطاطة الذهنية في السبعينيات( 1971) وكان ظهور أول استر اتيجية لخر ائط العقل على ألى

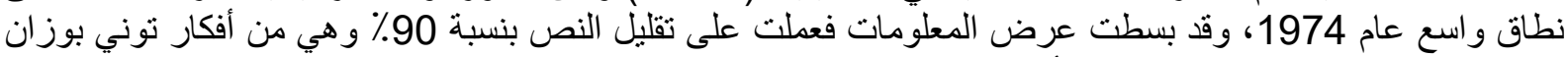

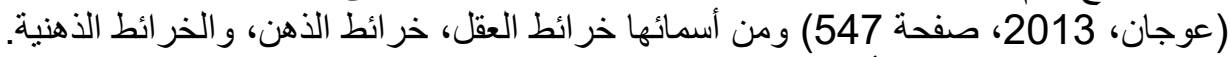

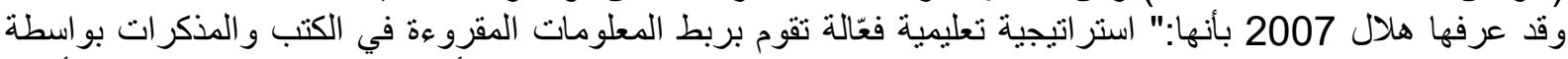

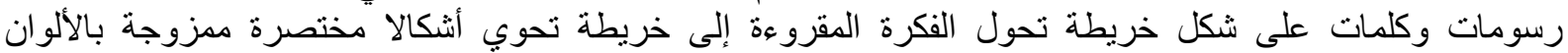

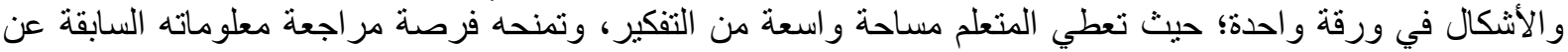

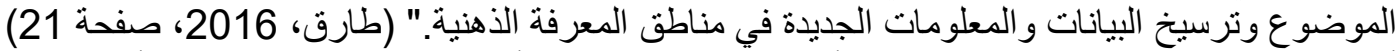

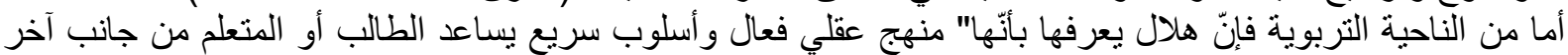

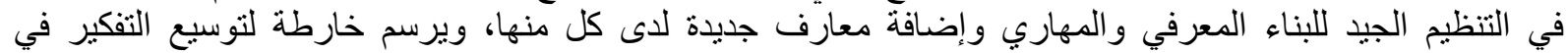

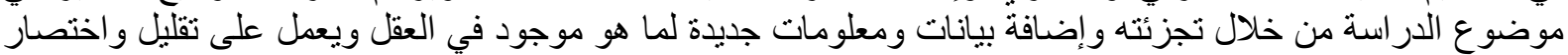

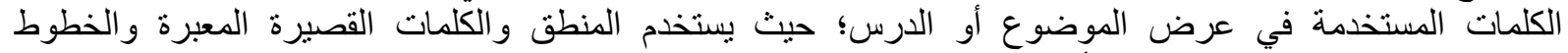

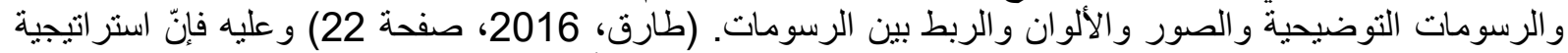

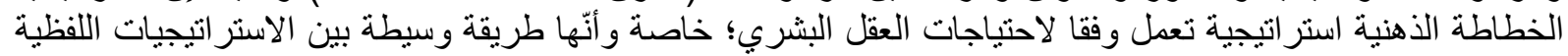

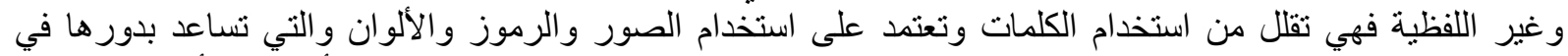

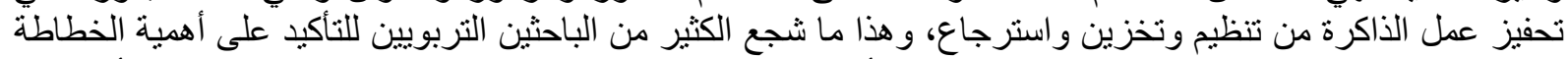

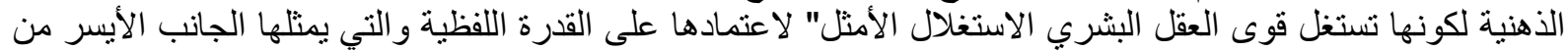

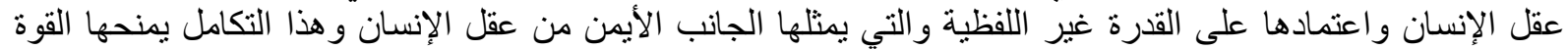

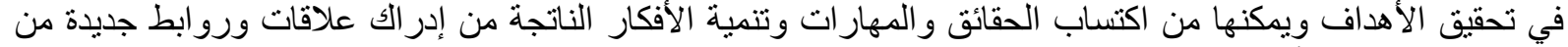

خلال الرسومات والألوان التي تحتويها." (طارق، 2016، صفحة 23)
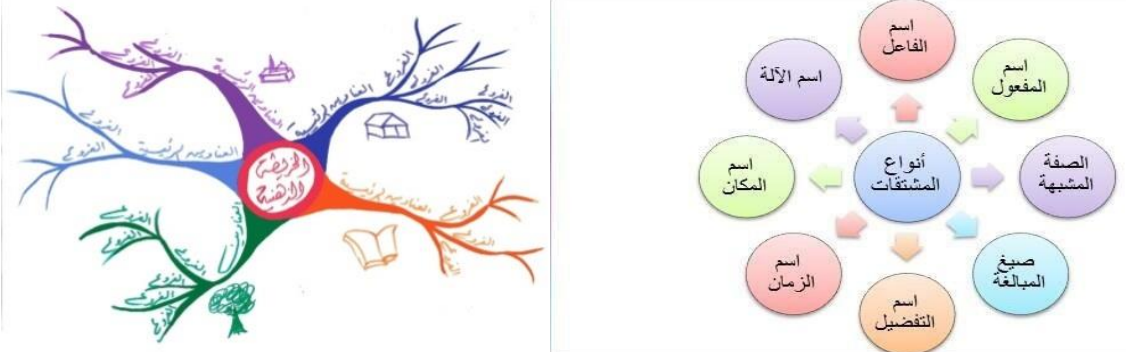

6. فوائد الخطاطة الذهنية: للخطاطة الذهنية فوائد كثيرة إذا ما استخدمها المتعلم الاستخدام الأمثل، واستخدامها في

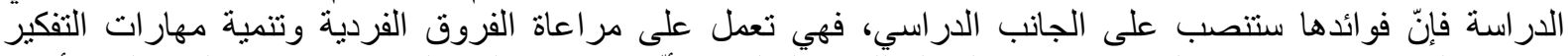

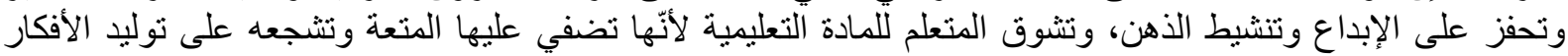

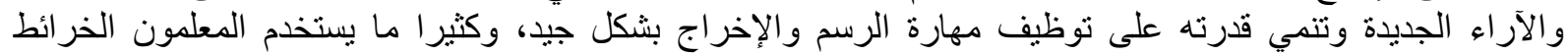




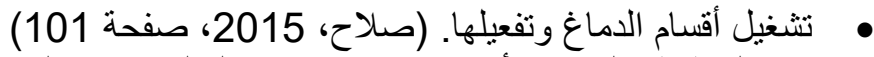
و الحديث عن الخطاطة الذهنية وأهيتها وفو ائدها في التعليم يعيدنا إلى الحديث عن أسسها النظرية، فنجد أنها تستند إلى"

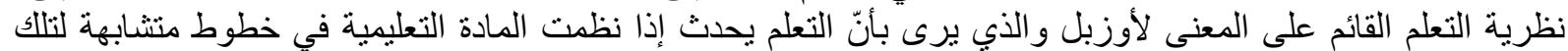

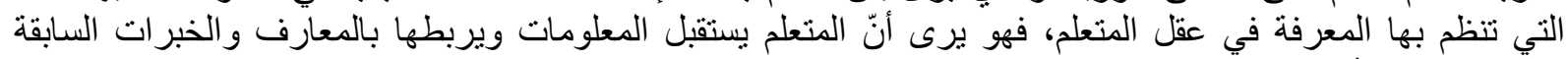

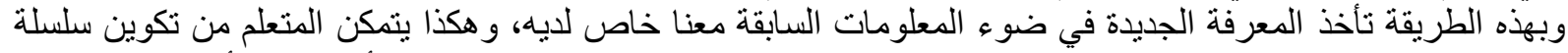

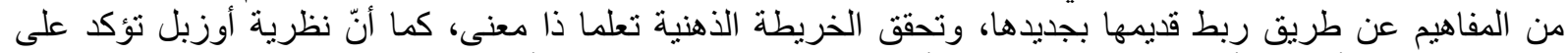

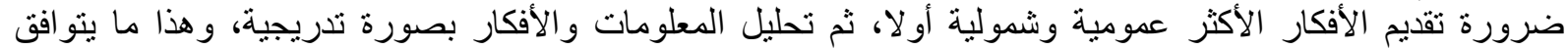
والخطاطة الذهنية.

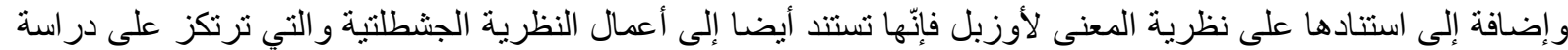

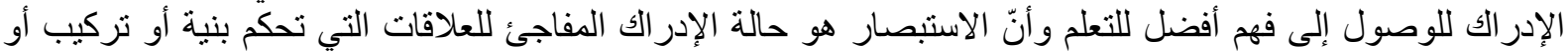

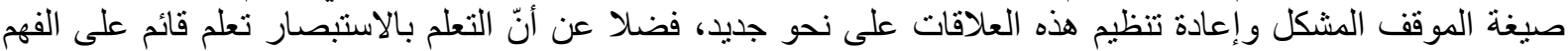

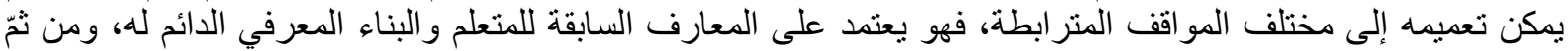

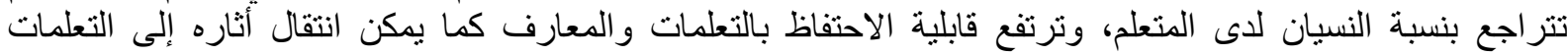
المشابهة له. اله. و عليه فقد أكد عديد الباحثين ومنهم مايكبيرج Maeckelbrg على أنّ الخطاطة الذهنية تثثير العقل ليدرك المتعلم الصورة

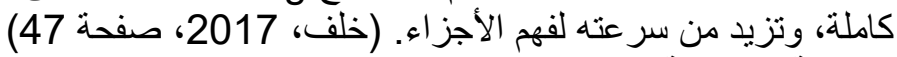

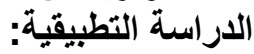
و لأنّ النحو من أهم فروع اللغة العربية، وكثير الما يعاني المتعلمون من صعوبات في تحصيل قو اعده النحوية ونوظيفها

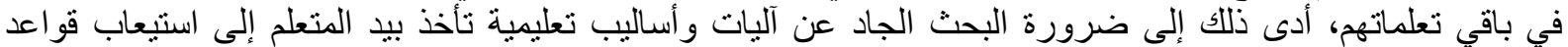

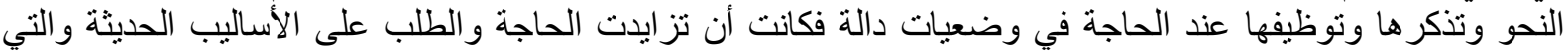

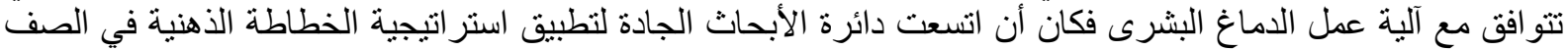

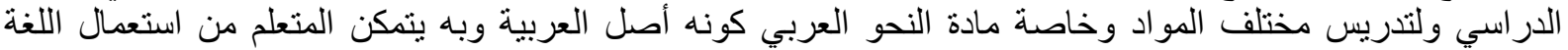

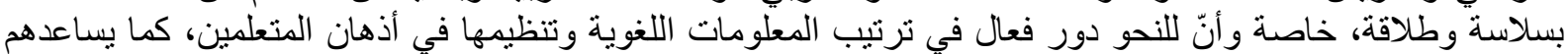

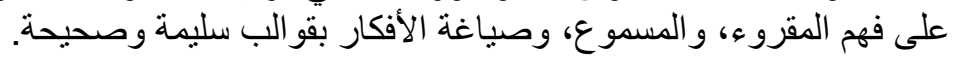

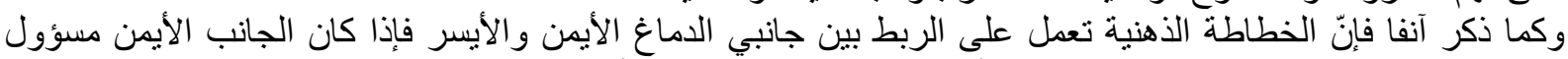

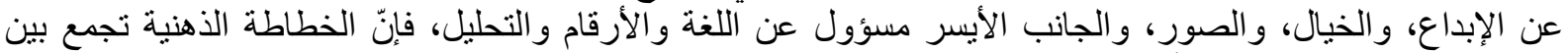

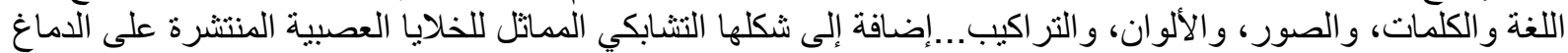

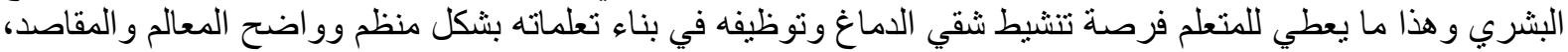

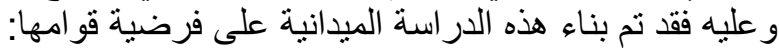

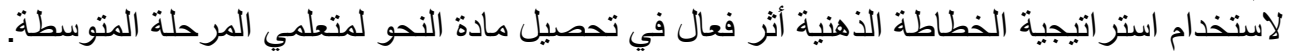

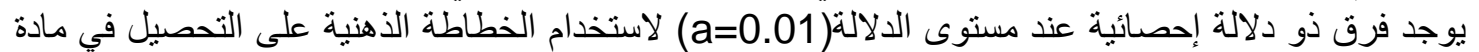
النحو لاى تلاميذ السنة الثالثة متوسط.

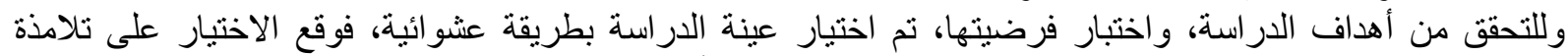

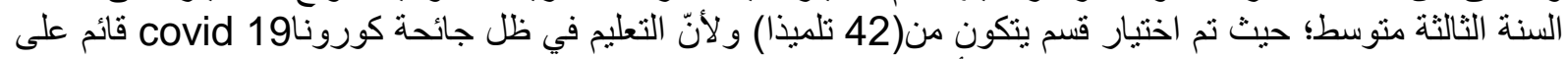

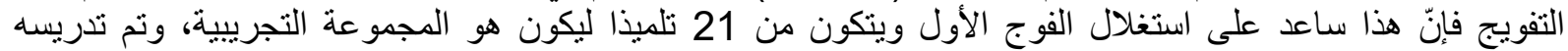

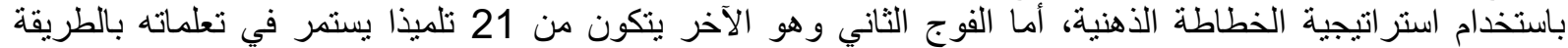

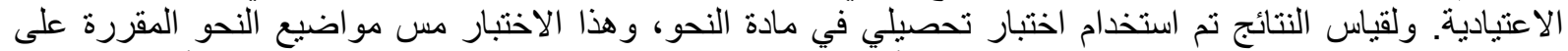

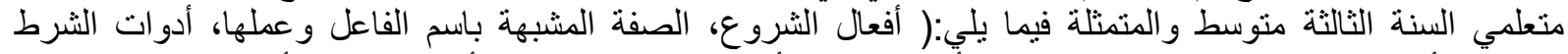

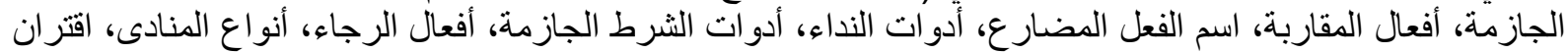

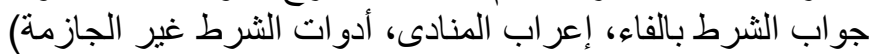




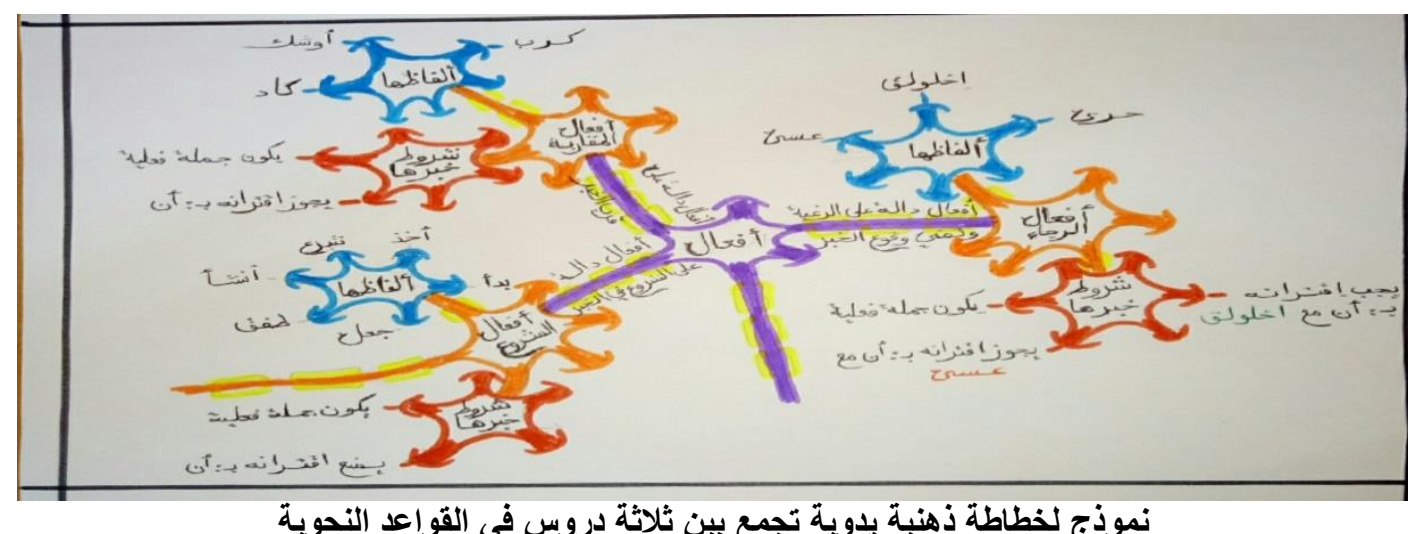

محددات الار اسة:

الفئة المستهدفة مجمو عة من تلاميذ السنة الثالثة متوسط.

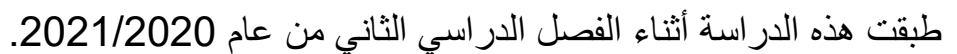

إجراءات الدراسة: استخدمت هذه الدراسة المنهج التجريبي للتوصل من خلال النتائج إلى أثر استخدام الخطاطة الذهنية

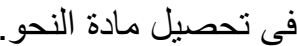

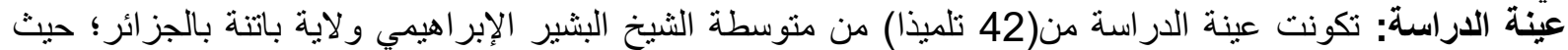

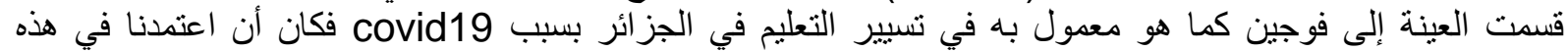

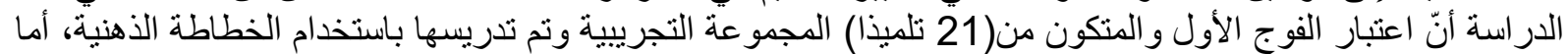

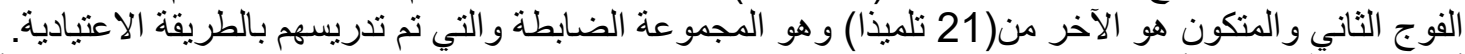

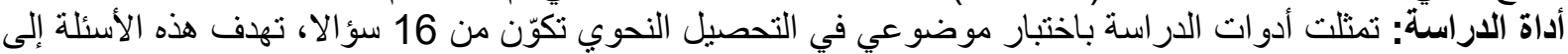

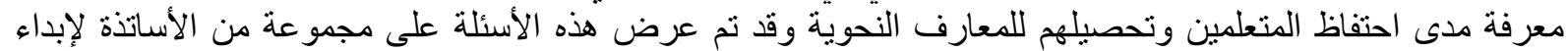

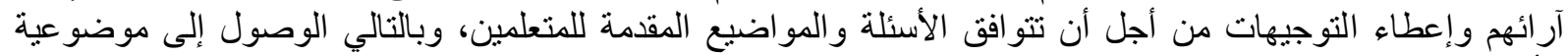
الأسئلة وصدقها. تطبيق أداة الدراسة: تم تطبيق الاختبار القبلي على المجموعتين التجريبية والضابطة، ثم تمّ رصد علامات التبات المتعلمين،

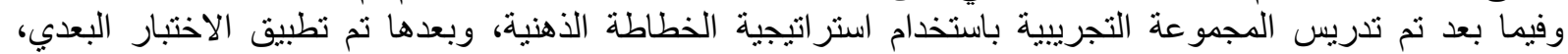
وحساب المتوسطات الحسابية والانحر افات المعيارية لنتائج متعلمي المجموعتين التجريبية والضابطة للاختبار القبلي و والبعدي. تصحيح اختبار الاراسة: نم تصحيح الاختبار بإعطاء كل تلميذ من تلاميذ المجمو عتين علامة عن كل إجابة صحيحة، وتم

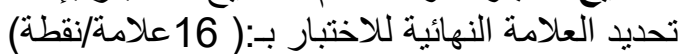

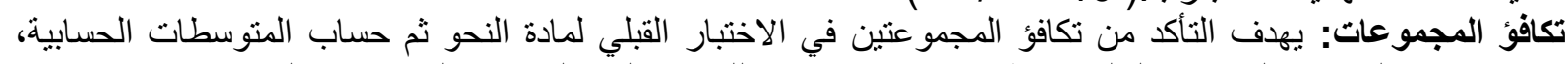

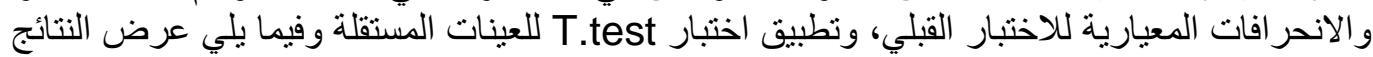
جدول نتائج اختبار T.test للعينات المستقلة للكثف عن الفروق بين المجمو عتين في القياس القبلي لاختبار مادة النحو(ن)

\begin{tabular}{|c|c|c|c|c|c|c|c|}
\hline القرار & الدلالة & الحرجية & $\mathrm{T}$ & الالحعراف & الحستوسي & & \\
\hline \multirow[t]{2}{*}{ غند 0.01 دال } & \multirow[t]{2}{*}{0.353} & \multirow[t]{2}{*}{20} & \multirow[t]{2}{*}{0.952} & 3.369 & 10.38 & الضنابطوة عة & \multirow[t]{2}{*}{ الإختبار } \\
\hline & & & & 2.040 & 10.81 & التجريبية عة & \\
\hline
\end{tabular}

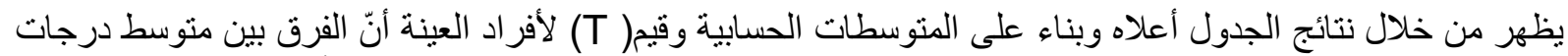

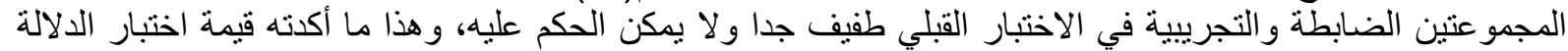

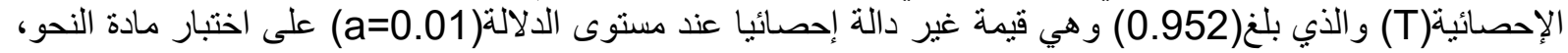

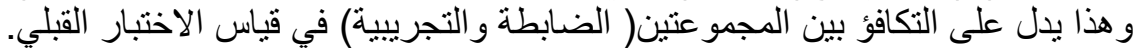

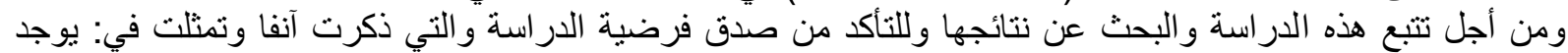

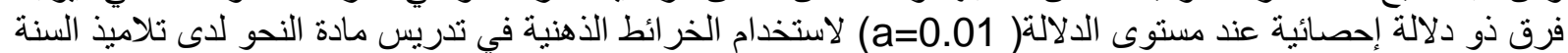


وللتحقق من صدق الفرضية تم تطبيق الاختبار البعدي على المجموعتين الضابطة والتجرييية، بعد أن نم تدريس

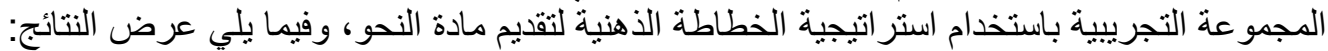
جدول نتائج اختبارT.test للعينات المستقلة للكثف عن الفروق بين الهجو عنين في القياس البعدي لاختبار مادة

\begin{tabular}{|c|c|c|c|c|c|c|c|}
\hline القرار & مستوى & الحرجة & $\mathrm{T}$ & الالمعياري اف & الحستبي & & \\
\hline \multirow[t]{2}{*}{ 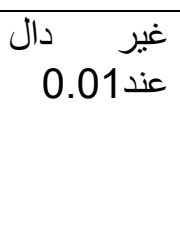 } & \multirow[t]{2}{*}{0.353} & \multirow[t]{2}{*}{20} & \multirow[t]{2}{*}{0.952} & 3.369 & 10.38 & الضابطو عل21 & \multirow[t]{2}{*}{ القبلي } \\
\hline & & & & 2.040 & 10.81 & التجرييية & \\
\hline \multirow[t]{2}{*}{ عندال 0.01} & \multirow[t]{2}{*}{0.002} & \multirow[t]{2}{*}{20} & \multirow[t]{2}{*}{3.553} & 3.155 & 10.57 & الضمابطو عة & \multirow[t]{2}{*}{ البعدي } \\
\hline & & & & 1.488 & 13.71 & التجريبية & \\
\hline
\end{tabular}

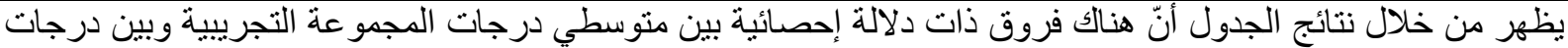

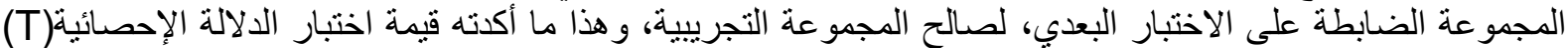

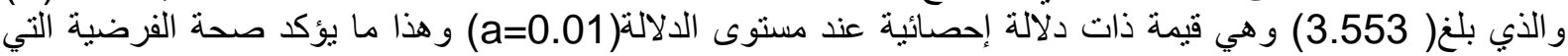

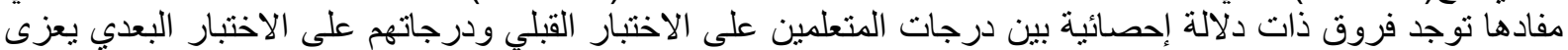

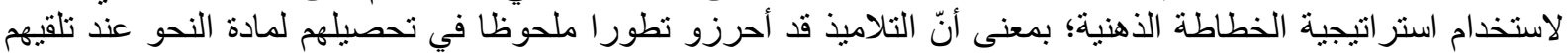

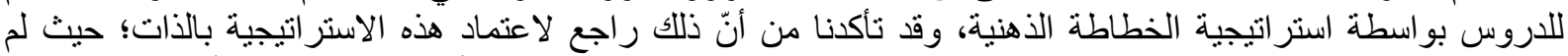

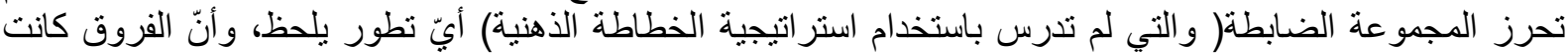

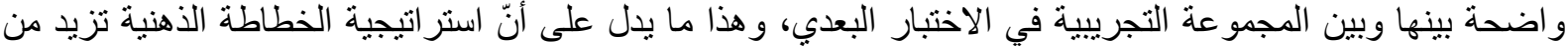
قدرة التلاميذ على اكتساب المفاهيم النحوية، وقدرتهم التحصيلية، وكذا سر عة استذكار هم للقو اعد النحوية.

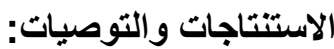

وفيما يلي عرض لأهم الاستنتاجات و التوصيات التي تم الوصول إليها من خلال هذه الورقة البحتية

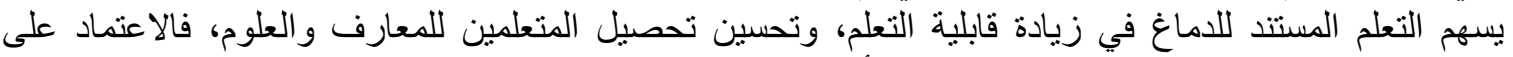
الخطاطة الذهنية كآلية من آليات عمل الذاعاغ أنثتت نجاعتها وفاعليتها في سرعة استيعاب وتحصيل المتعلمين

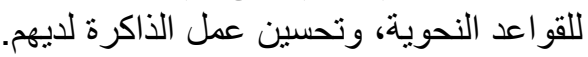
يخلق التعلم المستند للاماغ الدافعية لدى الدتعلمين و اقبالهم على التعلم، وتنظيم أعمالهم وترتيب أفكار هم بشكل يخدم تعلماتهم.

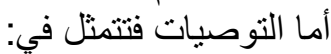
تدريب أساتذة اللغة العربية من خلال دورات تكوينية على إعداد مواضيع النحو وفقا لاستر اتيجية الخطاطة الذهنية وبما بتمانشى وقدر ات متعلميهم.

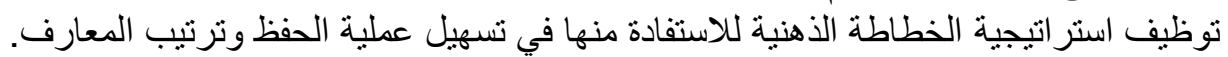

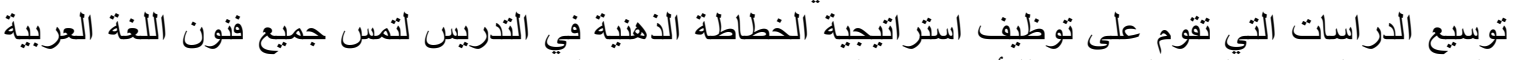

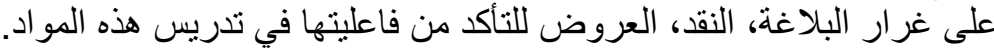

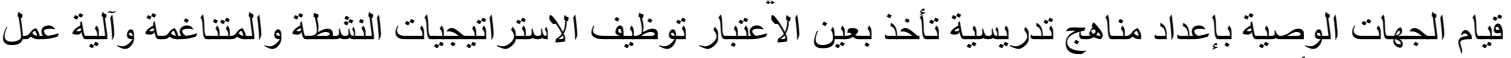
الأماغ و على رأسها استر اتيجية الخطاطة الذهنية.

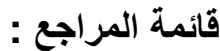

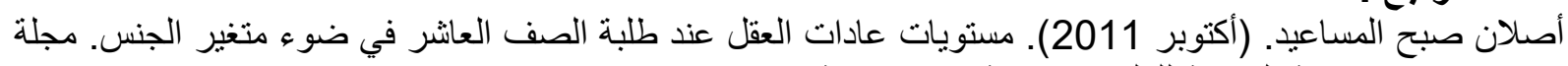

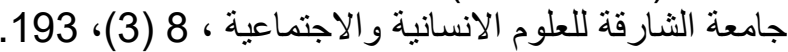
الزيات فتحي. (2003). سيكولوجية التعلم بين المنظور الارتباطية والنية المنظور المعرفي. دار النشر للجامعات. 
أمل السيد خلف. (2017). فاعلية برنامج قائم برنامج قائم على الخريطة الذهنية في تتمية بعض المفاهيم البيولوجية

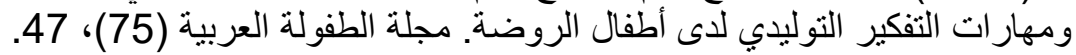

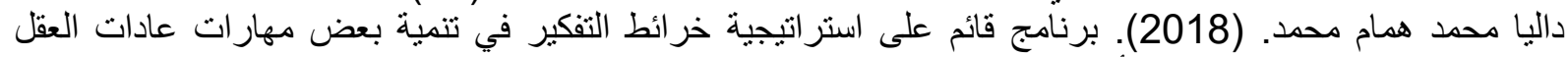

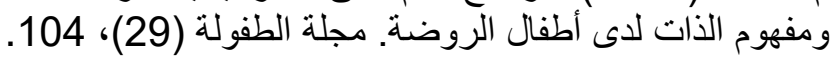

عبد الحسين وسام صلاح. (2015). التعلم المتناغم مع الدماغ تطبيقات الطفة (29)، لأبحاث الدماغ في التعلم (الإصدار ط1). دار الكتب العلمية.

عبد الرزاق عمار ـ (2017). التعليم و التعلم في الجامعة. مركز النشر الجامعي.

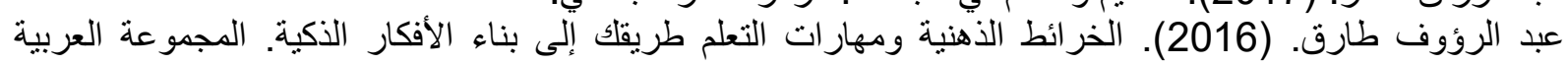
اللتدريب و النشر.

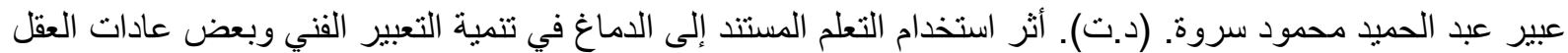

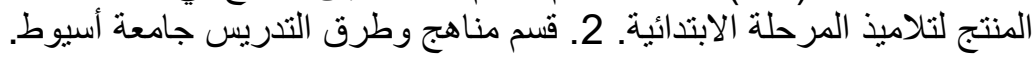

على لفته ماضي العبادي. (2017). فاعلية التدريس باساراتيجية التعلم المستند إلى الدماغ في في تحصيل مالتيل مادة الفيزياء والتفكير الجانبي لدى طلاب الصف الخامس الاعدادي التطبيقي. 9. (رسالة ماجستير ، المحرر) قسم العلوم فادئ

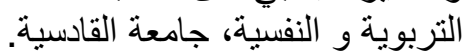

محمود عبد الرزاق مختار. (2016). فاعلية نموذح تدريسي في الأدب قائم على نظئم نظرية التعلم المستند إلى الدماغ في

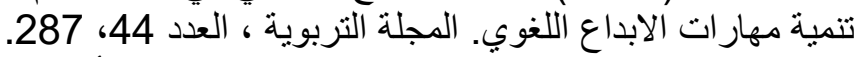

وسام صلاح عبد الحسين. (2015). التعلم المتناغم مع الدماغ تطبيقات لأبحاث الأبناث الدماغ في التعلم (الإصدار ط1). بيروت: دار الكتب العلمية.

وفاء سليمان عوجان. (2013). تصميم ودر اسة فاعلية برنامج تعليمي باستخدام الخر ائط الذهنية في تنمية مهار الات الأداء

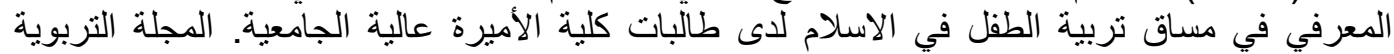

الدولية المتخصصة في ، 2 (6)، 547. 